\title{
On the Flame Height Definition for Upward Flame Spread
}

\author{
J.L. Consalvi ${ }^{* a}$, Y. Pizzo ${ }^{\text {a,b }}$, B. Porterie ${ }^{\text {a }}$ and J.L. Torero ${ }^{c}$ \\ ${ }^{a}$ Polytech'Marseille/DME, IUSTI/ UMR CNRS 6595, 5 rue E. Fermi, 13453 Marseille \\ Cedex 13, France \\ ${ }^{b}$ Institut de Radioprotection et de Sûreté Nucléaire, DPAM, Cadarache, 13108 Saint Paul \\ lez Durance, France \\ ${ }^{c}$ BRE/Edinburgh Centre for Fire Research, the University of Edinburgh, Edinburgh, \\ EH93JL, UK \\ *Corresponding author: Tel.: +33 491-106-927; Fax: +33-491-106-969. \\ E-mail address: Jean-Louis.Consalvi@polytech.univ-mrs.fr
}

\begin{abstract}
Flame height is defined by the experimentalists as the average position of the luminous flame and, consequently is not directly linked with a quantitative value of a physical parameter. To determine flame heights from both numerical and theoretical results, a more quantifiable criterion is needed to define flame heights and must be in agreement with the experiments to allow comparisons. For wall flames, steady wall flame experiments revealed that flame height may be defined by a threshold value on the wall heat flux. From steady wall flame measurements, three definitions of flame height from wall heat flux are retained: the first is based on the continuous flame while the two others are based on threshold values of $4 \mathrm{~kW} / \mathrm{m}^{2}$ and $10 \mathrm{~kW} / \mathrm{m}^{2}$. These definitions are applied to determine flame heights from a two-dimensional time-dependent CFD model used to describe flame spread along a slab of PMMA. Results show that the predicted flame heights are consistent with the available data of the literature. Defining flame height by threshold values on the wall heat flux of $4 \mathrm{~kW} / \mathrm{m}^{2}$ and $10 \mathrm{~kW} / \mathrm{m}^{2}$ allows to correlate the wall heat flux in term of $(\mathrm{x}-$
\end{abstract}


$\left.\mathrm{x}_{\mathrm{p}}\right) /\left(\mathrm{x}_{\mathrm{fl}}-\mathrm{X}_{\mathrm{p}}\right)$, which is the dimensionless characteristic length scale for upward flame spread. It is also found that the continuous flame is not a characteristic length for the heat transfer to the unburnt fuel and is not really appropriate to define flame height in upward flame spread.

Keywords: Upward Flame Spread; Steady wall flame; Flame Height Definition; Numerical Model

\section{Nomenclature}

A pre-exponential factor in the Arrhenius law [1/s]

$C_{P} \quad$ specific heat $[\mathrm{J} / \mathrm{kg} / \mathrm{K}]$

$f_{\text {soot }}$ soot volume fraction

$g$ gravitational acceleration $\left[\mathrm{m} / \mathrm{s}^{2}\right]$

G average incident radiation $\left[\mathrm{W} / \mathrm{m}^{2}\right]$

$h \quad$ enthalpy $[\mathrm{J} / \mathrm{kg}]$

$h_{\text {conv }}$ convection coefficient $\left[\mathrm{W} / \mathrm{m}^{2} / \mathrm{K}\right]$

I radiative intensity $\left[\mathrm{W} / \mathrm{m}^{2}\right]$

$k \quad$ turbulent kinetic energy $\left[\mathrm{m}^{2} / \mathrm{s}^{2}\right]$

$L_{v} \quad$ heat of vaporization $[\mathrm{J} / \mathrm{kg}]$

$m_{p}^{\prime \prime} \quad$ pyrolysate mass flux $\left[\mathrm{kg} / \mathrm{m}^{2} / \mathrm{s}\right]$

$n_{\text {soot }} \quad$ soot number density $\left[1 / \mathrm{m}^{3}\right]$

$p \quad$ pressure $[\mathrm{Pa}]$ 
$\dot{Q}^{\prime} \quad$ heat release rate per unit wall width $[\mathrm{W} / \mathrm{m}]$

$R \quad$ ideal gas constant $[\mathrm{J} / \mathrm{mol} / \mathrm{K}]$

$t$ time [s]

$T \quad$ temperature $[\mathrm{K}]$

$u \quad$ velocity $[\mathrm{m} / \mathrm{s}]$

$\mathrm{x} \quad$ coordinate along the slab surface [m]

$X \quad$ mole fraction

$x_{f l} \quad$ flame length [cm]

$x_{P} \quad$ pyrolysis length [mm or $\left.\mathrm{cm}\right]$

$\mathrm{y} \quad$ coordinate normal to the sample surface [m]

$Y \quad$ mass fraction

W molecular weight $[\mathrm{mol} / \mathrm{kg}]$

\section{Greek letters}

$\varepsilon \quad$ rate of dissipation of $\mathrm{k}\left[\mathrm{m}^{2} / \mathrm{s}^{3}\right]$, emissivity

$\kappa \quad$ radiant absorption coefficient $[1 / \mathrm{m}]$

$\lambda \quad$ thermal conductivity $[\mathrm{W} / \mathrm{m} / \mathrm{K}]$

$\rho \quad$ density $\left[\mathrm{Kg} / \mathrm{m}^{3}\right]$

$\omega \quad$ production rate $\left[\mathrm{kg} / \mathrm{m}^{3} / \mathrm{s}\right]$

\section{Subscripts}

$\alpha \quad$ species

$0 \quad$ ambient

p pyrolysis

Pr combustion products

rad radiant 

solid

\section{Introduction}

The spread of a flame over the surface of a solid combustible is a subject of interest in fire safety science because it influences the initial fire development and rate of heat release. In upward flame spread, the flame covers the solid element during the heating and pyrolysis processes and pyrolysed fuel is rapidly ignited by the flame after leaving the surface. The driving mechanism for upward spread has long been identified as heat transfer within the region that is being pre-heated suggesting that the characteristic length scale of the problem is the flame length minus the pyrolysis length $\left(\mathrm{x}_{\mathrm{fl}}-\mathrm{x}_{\mathrm{p}}\right)$ [1-3]. On the basis of this assumption many analytical models for upward flame spread have been developed $[4,5]$.

In most cases, closure of these models is obtained by using a relationship to correlate flame height as function of pyrolysis length. Several correlations on the form $x_{f l}=a x_{p}^{n}$ (where "a” and "n” are constants) obtained from both experimental [4-7] and numerical data [8] have been reported. Most of these data are relative to experiments with PMMA which has been intensively used in upward flame spread due to its well-known thermophysical properties. Saito et al. [5] suggest $n=2 / 3$ whereas Delichatsios [8] predicts $n=0.8$. Orloff et al. [4] report $\mathrm{n}=0.78$. Hasemi et al. [7] propose $\mathrm{n}=1$ and $\mathrm{a}=2$.

The use or validation of these models requires the knowledge of the pyrolysis and flame lengths. While the former can be obtained accurately with surface thermocouples, the definition and the measurements of flame height remain more ambiguous. Experimentalists 
usually define the flame height as the average position of the luminous flame. Nevertheless, the definition of the average position is one that varies with the experiment. For upward flame spread, most flame height measurements have been performed by using an eye-averaging of the flame tip location which clearly does not represent a systematic and reproducible technique [4-7]. Digital images have allowed to develop methods that systematically address this issue [8,9], nevertheless they all depend on the establishment of luminous intensity thresholds. The determination of a convenient threshold requires defining a reproducible and systematic procedure. Some examples of such a procedure can be found in [9-11].

An added task is the comparison between experimental data and numerical and theoretical model results where luminous intensity is a concept difficult to quantify. Conceptually, the flame height may be determined as the position along the wall where the average fuel concentration [8] or the Damkholer number [12] tends toward a critical value. If such a flame height definition seems convenient for both theoretical and numerical purposes, it is not easily applicable for flame height measurements.

Insight towards an alternate path has been obtained via steady wall flame experiments using liquid or gas burners and solid materials [10,13-15]. From dimensional analysis it has been shown that the flame length satisfies a relationship of the form $x_{f l}=a\left(\dot{Q}^{* *}\right)^{n} x_{p}$ where $\dot{Q}^{* *}=\frac{\dot{Q}^{\prime}}{\rho c_{p} T_{0} \sqrt{g x_{p}} x_{p}}$ is the Froude number [14]. These experiments have also revealed that wall heat fluxes are correlated in terms of $\mathrm{x} / \mathrm{x}_{\mathrm{fl}}$ using flame height as characteristic length scale. Given that upward flame spread is controlled by the transfer of heat from the flame to the material and that heat fluxes seem to correlate with the flame length, then it could be postulated that the flame length could be defined as a function of 
the heat flux. This approach is convenient for analytical, numerical and experimental studies, thus may be a way to conciliate experimental data with both theoretical and numerical results.

The aim of this paper is to explore the suitability of latter assertion using both experimental data from the literature and a complete time-dependent CFD (Computational Fluid Dynamics) model [11]. Model results concerning the time evolution of both pyrolysis and flame lengths have compared successfully with experiments [11]. Experimental data used will be flame heights and wall heat flux measurements in steady wall flames while the numerical tool will model upward flame spread. Data correspond to a number of fuels but the model focuses only on PMMA.

\section{Numerical Model}

The reactive flow is computed by solving the Favre density-weighted Navier-Stokes equations in connection with the RNG k- $\varepsilon$ turbulence model [16]. Near a solid surface, the velocity components parallel to the wall, the turbulent kinetic energy, and its rate of dissipation are treated through a local equilibrium wall log-law. The complete set of equations along with thermodynamic properties and equations of state can be found in [17]. The general form of the elliptic differential equations is given by

$$
\frac{\partial}{\partial t}(\rho \Phi)+\frac{\partial}{\partial x_{j}}\left(\rho u_{j} \Phi\right)=\frac{\partial}{\partial x_{j}}\left(\Gamma_{\Phi} \frac{\partial \Phi}{\partial x_{j}}\right)+S_{\Phi}
$$

The variable $\Phi$, the source terms, $S_{\Phi}$, and the effective exchange coefficients, $\Gamma_{\Phi}$, are listed in Table 1. The gas is assumed to be a mixture of perfect gases and, including the chemical energy in the mixture static enthalpy, the equations of state will take the form 
$p=\rho R T \sum_{\alpha} \frac{Y_{\alpha}}{W_{\alpha}}$

$h=\sum_{\alpha} Y_{\alpha}\left(\Delta h_{f \alpha}^{0}+\int_{T_{0}}^{T} C_{p \alpha}(T) d T\right)$

\subsection{Combustion Model}

In the present study, the Methyl-MethAcrylate (MMA)/air reactive system is modeled as a simplified one-step chemical reaction

$\mathrm{C}_{5} \mathrm{H}_{8} \mathrm{O}_{2}+6 \mathrm{O}_{2}+22.57 \mathrm{~N}_{2} \rightarrow 5 \mathrm{CO}_{2}+4 \mathrm{H}_{2} \mathrm{O}+22.57 \mathrm{~N}_{2}$

The consumption rate of fuel is calculated as the minimum of the Eddy Break-Up (EBU) expression [18] (mixing-controlled regime)

$\omega_{\text {mix }}=-4 \rho \frac{\varepsilon}{k} \min \left(Y_{C_{5} H_{8} O_{2}} ; \frac{Y_{O_{2}}}{s}\right)$

and an Arrhenius expression (kinetically-controlled regime) for MMA.

$\omega_{\text {kin }}=A \rho^{2} Y_{C_{5} H_{8} O_{2}} Y_{O_{2}} \exp \left(-T_{a c t} / T\right)$

with $\mathrm{A}=5.928 \times 10^{9} \mathrm{~m}^{3} /(\mathrm{Kg} \mathrm{s})$ and $\mathrm{T}_{\mathrm{act}}=1.07 \times 10^{4} \mathrm{~K}[19]$.

This extended form of the EBU which accounts for finite rate chemistry allows taking into account gas phase extinction at the trailing edge.

\subsection{Radiation Model}


In the radiation model, the grey assumption is used which implies that the absorption coefficient is independent of the wavelength of radiation. The model requires the solution of the radiative transfer equation (RTE)

$\vec{\nabla} \cdot[I(\vec{r} ; \vec{\Omega}) \vec{\Omega}]+\kappa_{a} I(\vec{r} ; \vec{\Omega})=\kappa_{a} I_{b}(T)$

where $\kappa_{\mathrm{a}}$ is the absorption coefficient that is found from the contributions from soot [20] and from the combustion products [18]

$$
\kappa=\kappa_{\text {soot }}+\kappa_{\mathrm{Pr}}=1862 f_{\text {soot }} T+0.1 X_{\mathrm{Pr}}
$$

The effects of radiation transport appear in the energy equation as the divergence of the radiative heat flux

$$
\frac{\partial q_{r j}^{\prime \prime}}{\partial x_{j}}=\kappa\left(G-4 \sigma T^{4}\right)
$$

where the average incident radiation, G, is defined by

$$
G=\int_{4 \pi} I(\vec{r} ; \vec{\Omega}) d \Omega
$$

\subsection{Soot Formation Model}

Concerning the soot formation model, the solution of two additional conservation equations for the soot mass fraction and number density is required. The model proposed by Moss et al. [21], in which the processes of nucleation, heterogeneous surface growth, and coagulation are included, is considered. To describe the mechanism of soot oxidation, the model of Naggle and Strickand-Constable [22] is added. Thus 


$$
\begin{aligned}
\omega_{\text {fsoot }}= & \frac{\rho^{3}}{\rho_{\text {soot }}} C_{\delta} C_{\alpha} T^{1 / 2} X_{f u} \exp \left(-T_{\alpha} / T\right)+\frac{\rho^{2}}{\rho_{\text {soot }}} C_{\gamma} n_{\text {soot }} T^{1 / 2} X_{f u} \exp \left(-T_{\gamma} / T\right)- \\
& \frac{\rho}{\rho_{\text {soot }}}(36 \pi)^{1 / 3} W_{\text {NSC }} n_{\text {soot }}^{1 / 3} f_{\text {soot }}^{2 / 3} \\
\omega_{\text {nsoot }}= & C_{\alpha} N_{0} \rho^{3} T^{1 / 2} X_{f u} \exp \left(-T_{\alpha} / T\right)-\rho C_{\beta} T^{1 / 2} n_{\text {soot }}^{2} / N_{0}
\end{aligned}
$$

where $\rho_{\text {soot }}=1800 \mathrm{~kg} / \mathrm{m}^{3}$. For MMA, Moss et al. [21] propose the following constants:

$\mathrm{C}_{\alpha}=3.68 \times 10^{5} \mathrm{~m}^{3} /\left(\mathrm{kgK}^{1 / 2} \mathrm{~s}\right), \quad \mathrm{C}_{\beta}=2 \times 10^{9} \mathrm{~m}^{3} /\left(\mathrm{K}^{1 / 2} \mathrm{~s}\right), \quad \mathrm{C}_{\gamma}=8.5 \times 10^{-13} \mathrm{~m}^{3} /\left(\mathrm{K}^{1 / 2} \mathrm{~s}\right), \mathrm{C}_{\delta}=144$, $\mathrm{T}_{\alpha}=46000 \mathrm{~K}, \mathrm{~T}_{\gamma}=12600 \mathrm{~K}$. $\mathrm{W}_{\mathrm{NSC}}$ is the oxidation rate of soot due to $\mathrm{O}_{2}$.

\subsection{Pyrolysis model}

The volatilisation of PMMA is modelled as a phase change at a constant surface temperature of $630 \mathrm{~K}$.

In the solid, the one-dimensional heat transfer equation

$$
\rho_{s} C_{p s} \frac{\partial T_{s}}{\partial t}=\frac{\partial}{\partial x}\left(\lambda_{s} \frac{\partial T_{s}}{\partial x}\right)
$$

is solved and surface regression is neglected.

At the solid surface exposed to the flame the boundary conditions are as follows

- Before pyrolysis

$$
-\lambda_{s} \frac{\partial T_{s}}{\partial x}=h_{\text {conv }}\left(T-T_{s}\right)+\varepsilon_{s}\left(q_{r a d}^{\prime \prime}-\sigma T_{s}^{4}\right)
$$


- After pyrolysis:

$$
\begin{aligned}
& T_{s}=T_{i g} \\
& -\lambda_{s} \frac{\partial T_{s}}{\partial x}+m_{p}^{\prime \prime} L_{v}=h_{\text {conv }}\left(T-T_{s}\right)+\varepsilon_{s}\left(q_{\text {rad }}^{\prime \prime}-\sigma T^{4}\right)
\end{aligned}
$$

At the rear surface of the slab, the boundary condition is:

$\lambda_{s} \frac{\partial T_{s}}{\partial x}=h_{c o n v}\left(T_{s}-T\right)+\varepsilon_{s}\left(q_{r a d}^{\prime \prime}-\sigma T_{a m b}^{4}\right)$

The incident radiative flux, $q_{\text {rad }}^{\prime \prime}$, that appears in Eqs. (14)- (16), is computed from the radiation model.

\subsection{Numerical Procedure}

The conservation equations are discretized on a staggered, non-uniform Cartesian grid by a finite-volume procedure with a second-order backward Euler scheme for time integration. Diffusion terms are approximated from a second-order central difference scheme. For the convective terms, the ULTRASHARP approach [23] is used. The pressure-velocity linked equations are solved using the Iterative PISO algorithm [24]. The RTE is solved using the FVM with a $2 \times 16$ angular mesh [25]. The heat and mass transfer conjugated problem at the gas solid interface is treated through a blocked-off region procedure [17].

\subsection{Computational Details}

The physical problem involves a $10 \mathrm{~cm} \times 120 \mathrm{~cm}$ domain. A $2.5 \mathrm{~cm} \times 60 \mathrm{~cm}$ PMMA slab is located at $7.5 \mathrm{~cm}$ from the west boundary. A non-uniform mesh with $60 \times 460$ cells is used and the time step is $0.02 \mathrm{~s}$. The origin of the coordinate axis is the bottom exposed corner of 
the PMMA slab (Fig.1). Ignition is produced by means of a radiative heat flux exposure. The ignition flux is eliminated immediately after the onset of the combustion reaction. Time zero is defined as the instant when the fuel surface attains the pyrolysis temperature.

The values of the thermal properties of the PMMA adopted in this study are $\rho_{\mathrm{s}}=1200 \mathrm{~kg} / \mathrm{m}^{3}, \lambda_{\mathrm{s}}=0.1874 \mathrm{~W} / \mathrm{m}^{2} / \mathrm{K}, \mathrm{C}_{\mathrm{ps}}=1400 \mathrm{~J} / \mathrm{kg} / \mathrm{K} \mathrm{T} \mathrm{T}_{\mathrm{p}}=630 \mathrm{~K}, \varepsilon_{\mathrm{s}}=0.95, \mathrm{~L}_{\mathrm{v}}=1.625 \times 10^{6} \mathrm{~J} / \mathrm{kg}$. These thermal properties are consistent with literature data (see [26] for example).

\section{Results and Discussion}

Figure 2 shows the wall heat flux as function of $\mathrm{x} / \mathrm{x}_{\mathrm{fl}}$ obtained from steady wall experiments using liquid [15], gaseous [10,14] and solid fuels [13]. These experiments represent a very wide range of conditions. Ahmad and Faeth [15] used a 660mm wide burner with side walls and varied the length of the burner from $51 \mathrm{~mm}$ to $152 \mathrm{~mm}$. The fuels tested were propanol, ethanol, and methanol to minimize soot radiation. Coutin [10] used propane burners of width $40 \mathrm{~cm}$. Measurements of wall heat flux and flame heights have been performed using two burner heights of $0.5 \mathrm{~m}$ and $1 \mathrm{~m}$ respectively. For each burner height, different rates of heat release were considered. Hasemi [14] used 37.5 mm wide by $82 \mathrm{~mm}$ methane burners placed against a wall in an enclosure of $2.8 \mathrm{~m}$ x $2.8 \mathrm{~m}$ x $2.18 \mathrm{~m}$. Quintiere et al. [13] used $28 \mathrm{~cm} \times 28 \mathrm{~cm}$ samples of solid materials and for each material several tests were performed applying different external heat fluxes on the sample in order to modify the burning rate. Figure 2 also shows that wall heat fluxes are correlated in terms of $\mathrm{x} / \mathrm{x}_{\mathrm{fl}}$. Nevertheless the plot has been divided into two since the data from reference [10] do not match all other tests. Data presented in Fig. 2(a) were compiled by Quintiere et al. [13] and the discrepancies of those of Coutin [10] (Fig. 2(b)) can be directly attributable to a difference in the definition of flame height. While Ahmad and Faeth [15] avoid making a 
definition of flame height and only use the burner length as characteristic length scale, Hasemi [14] and Quintiere et al. [13] define flame height by several methods, detecting the onset of temperature rise $\left(10^{\circ} \mathrm{C}\right)$ or as the uppermost position of the luminous flame by either direct visual estimates, single film images or short-time averaging of individual video frames. In contrast, Coutin [10] defines the flame tip by the average position of the luminous flame using an extension of a technique that is well documented in [9]. From comparing Fig. 2(a) and 2(b) it can be clearly seen that differences of the wall heat flux of the order of $50 \%$ can be generated by inconsistent definition of the flame height.

It is nevertheless clear from Fig. 2 that independent of the scaling value used, heat fluxes correlate well with the flame tip height and an alternate approach can be used to define this characteristic value. Since heat flux to the fuel surface control flame spread it will be natural to define the flame height as a function of a quantifiable heat flux threshold. This will suit well experimental, analytical and numerical studies. Given the definitions used by the different authors Fig. 2(a) shows that the flame height corresponds to the location where the wall heat flux is reduced to approximately $4 \mathrm{~kW} / \mathrm{m}^{2}$ whereas Fig. 2(b) suggests defining flame height by a threshold value on the wall heat flux of about $10 \mathrm{~kW} / \mathrm{m}^{2}$.

An alternate approach, that will be independent of the scaling used, may consist in defining flame height as the uppermost position of the continuous flame, i.e. the region experiencing an almost constant heat flux. This latter definition seems to be easier to interpret. To assess the validity of this approach the wall heat flux has been modelled and results are presented in Fig. 3 where the convective, incident radiative and total fluxes determined from the numerical model are plotted as a function of $\mathrm{x} / \mathrm{x}_{\mathrm{p}}$. It appears that the region of rapid decrease in the average radiative flux corresponds globally to the uppermost position of the continuous flame. 
The different definitions of flame height have been tested using the numerical model and the results are presented in Fig. 4 together with the experimental data for PMMA [4, 6, 7, 11]. The correlation proposed by Delichatsios [8] is also included in Fig. 4. Flame heights have been determined from the numerical results by using the three definitions: threshold values on the wall heat flux of $4 \mathrm{~kW} / \mathrm{m}^{2}$ and $10 \mathrm{~kW} / \mathrm{m}^{2}$, and the uppermost position of the continuous flame. Since a wall heat flux of $4 \mathrm{~kW} / \mathrm{m}^{2}$ and the uppermost position of the continuous flame are connected to the highest and lowest positions of the intermittent flame, respectively, most of the experimental data falls between them. Flame height data reported by Orloff et al. [4] are in relative good agreement with the model when the definition of the flame height is a threshold value on the wall heat flux of $4 \mathrm{~kW} / \mathrm{m}^{2}$. On the contrary the data reported in [6] and [11] seems to follow globally the same trend as the continuous flame. The flame tip heights measured by Hasemi et al. [7] are close to the predicted continuous flame heights for pyrolysis heights less than $30 \mathrm{~cm}$. For pyrolysis lengths greater than $40 \mathrm{~cm}$, they become closer to the correlation of Delichatsios [8], to the data of Orloff et al [4] and to the model when the definition of the flame height is a threshold value on the wall heat flux of $4 \mathrm{~kW} / \mathrm{m}^{2}$. Clearly, the discrepancies between experimental data and the different models may be attributed to the fact that the measurements have been performed using different techniques. Nevertheless, Fig. 4 serves to show the potential advantages of defining the flame length by means of a wall heat flux.

As previously mentioned, the process of flame spread is controlled by heat transfer downstream of the pyrolysis region. Thus the characteristic length of interest is not the flame length but $\left(\mathrm{x}_{\mathrm{fl}}-\mathrm{X}_{\mathrm{p}}\right)$. It is therefore important to understand how the heat flux distribution behaves when scaled by this characteristic length. Figures 5, 6, and 7 provide the wall heat flux in terms of $\left(\mathrm{x}-\mathrm{x}_{\mathrm{p}}\right) /\left(\mathrm{x}_{\mathrm{fl}}-\mathrm{x}_{\mathrm{p}}\right)$. Fig. 5 defines the flame length as the 
continuous flame length, $\mathrm{x}_{\mathrm{fl}, \mathrm{c}}$, Fig. 6 uses a $4 \mathrm{~kW} / \mathrm{m}^{2}$ threshold, $\mathrm{x}_{\mathrm{fl}, 4}$, and Fig. 7 the 10 $\mathrm{kW} / \mathrm{m}^{2}$ threshold, $\mathrm{x}_{\mathrm{fl}, 10}$. Experimental data for steady flames were extracted from [10] and [13]. Although the continuous flame definition correlates well the numerical solutions (Fig. 5(b)), it is clear that the experimental data diverges quite significantly (Fig.5(a)). Better correlations can be obtained using both wall heat flux thresholds with the highest threshold correlating best the empirical data (Fig. 7(a)). Materials such as particle board, carpet or aircraft panels will tend to char and provide an unclear definition of the continuous flame. For these latter materials, the continuous flame height is very close to the pyrolysis front and in some cases (not represented in Fig. 5(a)), continuous flaming can occur under the sample's pyrolysis region. These results suggest that the continuous flame is not a relevant length scale for heat transfer during upward flame spread and cannot be used to define flame height. For the data presented, the experimental definition of the flame height is best represented by the $10 \mathrm{~kW} / \mathrm{m}^{2}$ wall heat flux threshold. It is important to mention that by redefining the flame length and using $\left(\mathrm{x}_{\mathrm{fl}}-\mathrm{X}_{\mathrm{p}}\right)$ as characteristic length scale the data of Figs. 2(a) and 2(b) converge.

Fig. 8 shows the wall heat flux distributions obtained by the model for different pyrolysis length as function of $\left(\mathrm{x}-\mathrm{x}_{\mathrm{p}}\right) /\left(\mathrm{x}_{\mathrm{fl}}-\mathrm{x}_{\mathrm{p}}\right)$. In these cases $\mathrm{x}_{\mathrm{fl}}$ is defined using the relationships from the literature of the form $x_{f l}=a x_{p}^{n}$. The constants " $\mathrm{a}$ " and " $\mathrm{n}$ " for the different correlations are listed in Table 2. Results show that the only the relationship that correlates well the wall heat flux in terms of $\left(\mathrm{x}-\mathrm{x}_{\mathrm{p}}\right) /\left(\mathrm{x}_{\mathrm{fl}}-\mathrm{X}_{\mathrm{p}}\right)$ is that given by Tewarson and Ogden [6] (Fig. 8(d)). None of the other flame length definitions (Figs. 8 (a), (b) and (c)) allow correlating the numerical results. Detailed attention to the article of Tewarson and Ogden [6] shows that they observed that that their measured flame tip height corresponded to a wall heat flux of about $12 \mathrm{~kW} / \mathrm{m}^{2}$. These observations confirm that a threshold heat flux 
seems to be the best way to define the flame height. The results of Figs. 5-8 show best convergence for higher thresholds and thus seem to indicate that any threshold close to the onset of the decay region will lead to the best results.

Most of the results used correspond to steady burning, thus it must be underlined that upward flame spread induced a supplementary difficulty on flame height measurements compared to steady wall flame, due to the evolution of the burning rate during averaging procedures. This is illustrated in Fig. 9 where $\frac{\Delta \dot{\mathrm{Q}}_{\mathrm{t}}^{\prime}}{\dot{\mathrm{Q}}_{\mathrm{t}}^{\prime}}=\frac{\dot{\mathrm{Q}}_{\mathrm{t}+\Delta \mathrm{t}}^{\prime}-\dot{\mathrm{Q}}_{\mathrm{t}}^{\prime}}{\dot{\mathrm{Q}}_{\mathrm{t}}^{\prime}}$ is plotted as function of the pyrolysis length. $\dot{Q}_{t}^{\prime}=\chi_{c h} \Delta H_{c} \int_{0}^{x_{p}} m_{p}^{\prime \prime} d x$ is the rate of heat release per unit width. The value of $\Delta \mathrm{t}$ is the time period through which images are averaged to obtain the flame length. The averaging time for flame height measurement is assumed to be $10 \mathrm{~s}$ in agreement with previous upward flame spread experiments [11]. Fig. 9 shows that the variation of the burning rate during the averaging period for flame height measurements is greater than $10 \%$ for $\mathrm{x}_{\mathrm{p}}$ less than $3 \mathrm{~cm}$. For pyrolysis lengths from $3 \mathrm{~cm}$ to about $20 \mathrm{~cm}$, it decreases to reach about $4 \%$ before increasing slightly due to the acceleration in rate of spread. However, despite the high value near the leading edge, the variation of burning rate during flame height measurement does generally not exceed $7 \%$. Thus, steady measurements and propagating flame measurements could be treated in a similar manner so long the averaging interval, $\Delta \mathrm{t}$, remains small.

\section{Concluding remarks}

The viability of defining the flame height from a threshold wall heat flux has been explored.

The following conclusions can be drawn: 
1) Such a definition provides a quantitative way to determine flame height from both experimental data, numerical and theoretical models.

2) Three definitions of flame height, namely the continuous flame and threshold values on the wall heat flux of $4 \mathrm{~kW} / \mathrm{m}^{2}$ and $10 \mathrm{~kW} / \mathrm{m}^{2}$, have been deduced from steady wall flame measurements. These definitions have been applied to determine flame heights from a CFD model used to describe upward flame spread. Predicted results are consistent with previous experimental data.

3) The definition of the flame height by a threshold value on the wall heat flux of $4 \mathrm{~kW} / \mathrm{m}^{2}$ and $10 \mathrm{~kW} / \mathrm{m}^{2}$ allows to correlate the wall heat flux in term of $\left(\mathrm{x}-\mathrm{x}_{\mathrm{p}}\right) /\left(\mathrm{x}_{\mathrm{fl}}-\mathrm{x}_{\mathrm{p}}\right)$. The best correlation is obtained for $10 \mathrm{~kW} / \mathrm{m}^{2}$ but functions established via correlations showed that higher thresholds provide equally good results $\left(12 \mathrm{~kW} / \mathrm{m}^{2}\right)$.

4) The continuous flame is not an appropriate definition for the flame length since continuous flaming can occur very close to the pyrolysis front, especially for charring materials.

\section{Acknowledgements}

The funding for J.L. Consalvi, Y. Pizzo and B. Porterie was provided by IRSN while funding for J.L. Torero was provided by NASA Fire Safety Program of the Bioastronautics Initiative, grant \# NAG-32568.

\section{References}

[1] Fernandez-Pello AC. The Solid Phase. In: Cox G editor. Combustion Fundamentals of Fire. Academic Press, San Diego, 1995, pp. 31-100.

[2] Fernandez-Pello AC, Hirano T. Controlling Mechanisms of Flame Spread. Combust Sci Technol 1983;32:1-31. 
[3] Fernandez-Pello AC. Flame Spread Modeling. Combust Sci Technol 1984;39:119-134.

[4] Orloff L, de Ris J, Markstein GH. Upward Turbulent Fire Spread and Burning of Fuel Surface. $15^{\text {th }}$ Symposium (int.) on Combustion, The Combustion Institute, 1974. p. 183-92.

[5] Saito K, Quintiere JG, Williams FA. Upward Turbulent Flame Spread. Fire Saf Sci; Proceedings of the First International Symposium, 1985, p. 75-86.

[6] Tewarson A, Ogden SD. Fire Behavior of Polymethylmethacrylate. Combust Flame 1992;89:237-259.

[7] Hasemi Y, Yoshida M, Nohara A, Nakabayashi T. Unsteady-State Upward Flame Spreading Velocity along Vertical Combustible Solid and Influence of External Radiation on the Flame Spread. Fire Saf Sci; Proceedings of the Third International Symposium, 1991, p. 197-206.

[8] Delichatsios MA. Flame Heights in Turbulent Wall Fires with Significant Flame Radiation. Combust Sci Technol 1984;39:195-214.

[9] Audouin L, Kolb G, Torero JL, Most JM. Average Centerline Temperature of a Buoyant Pool Fire Obtained by Image Processing of Video Recordings. Fire Safety J 1995;24:167-187.

[10] Coutin M. Etude Expérimentale et Théorique de l'Influence de l'Entraînement d'Air sur le Comportement d'une Flamme Représentative d'un Incendie. PhD Thesis, Université de Poitiers, France: 2000.

[11] Consalvi JL, Porterie B, Coutin, M, Audouin L, Casselman C, Rangwala A, Buckley SG, Torero JL. Diffusion Flames Upwardly Propagating over PMMA. Fire Saf Sci; Proceedings of the Eighth International Symposium, 2005, p. 397-408. 
[12] Torero JL, Vietoris T, Legros G, Joulain P. Estimation of a Total Mass transfer Number from the Stand-off Distance of a Spreading Flame. Combust Sci Technol 2002;174:187-203.

[13] Quintiere J, Harkleroad M, Hasemi Y. Wall Flames and Implications of Upward Flame Spread. Combust Sci Technol 1986;48:191-222.

[14] Hasemi Y. Thermal Modelling of Upward Wall Flame Spread. Fire Saf Sci; Proceedings of the First International Symposium, 1985, p. 87-96.

[15] Ahmad T, Faeth G.M. Turbulent Wall Fire. $17^{\text {th }}$ Symposium (Int.) on Combustion, The Combustion Institute, 1979, p. 1149-60.

[16] Yakhot V, Orszag S. Renormalization Group Analysis of Turbulence. J of Scientific Computing 1986; 1:3-51.

[17] Consalvi JL, Porterie B, Loraud JC. A Blocked-off Region Strategy to Compute Fire Spread Scenarios Involving Internal Flammable Target. Numerical Heat Transfer B 2005;47:419-441.

[18] Magnussen BF, Hjertager BH. On Mathematical Modeling of Turbulent Combustion with Special Emphasis on Soot Formation and Combustion. $16^{\text {th }}$ Symposium (Int.) on Combustion, The Combustion Institute, 1976, p. 719-29.

[19] Fernandez-Pello AC, Ray SR, Glassman I. Flame Spread in an Opposed Forced Flow: The Effect of Ambient Oxygen Concentration. $18^{\text {th }}$ Symposium (Int.) on Combustion, The Combustion Institute, 1981, p. 579-89.

[20] Kent JH, Honnery DR. A Soot Formation Rate Map for a Laminar Ethylene Diffusion Flame. Combust Flame 1990;79:287-298.

[21] Moss JB, Stewart CD. Flamelet-based Smoke Properties for Field Modelling of Fires. Fire Safety J 1998;30:229-250. 
[22] Nagle J, Strickland-Constable RF. Oxidation of Carbon between $1000-2000^{\circ} \mathrm{C}$. Fifth (Int.) Carbon Conference, 1962, p. 154-64.

[23] Leonard BP, Drummond JE. Why You Should Not Use Hybrid, Power-Law or Related Exponential Schemes for Convective Modelling. There Are Much Better Alternatives. Int J Numerical Method in Fluids 1995;20:421-442.

[24] Chow WK, Cheung YL. Selection of Differencing Scheme on Simulating the Sprinkler Hot-Air Layer Problem. Numerical Heat Transfer A 1999;35:311-330.

[25] Raithby GD, Chui EH, A Finite Volume Method for Predicting a Radiant Heat Transfer in Enclosures with Participating Media. J Heat Transfer 1990;112:415-423.

[26] Zhou YY, Walther DC, Fernandez-Pello AC. Numerical Analysis of Piloted Ignition of Polymeric Material. Combust Flame 2002;31:147-158. 


\section{List of Figure Captions}

Figure 1: A schematic of the physical problem.

Figure2: Wall heat flux as function of $\mathrm{x} / \mathrm{x}_{\mathrm{fl}}$ : (a) Experimental data from Ref. [13]- [15], (b) Experimental data from Ref. [10].

Figure 3: Total, incident radiative, and convective heat fluxes as function of $x / x_{p}$.

Figure 4: Flame height as function of the pyrolysis length.

Figure 5: Wall heat flux as function of $\left(\mathrm{x}-\mathrm{x}_{\mathrm{p}}\right) /\left(\mathrm{x}_{\mathrm{fl}}-\mathrm{x}_{\mathrm{p}}\right)$ using the continuous flame to define flame height: (a) experimental data, (b) numerical results for different pyrolysis lengths.

Figure 6: Wall heat flux as function of $\left(\mathrm{x}-\mathrm{x}_{\mathrm{p}}\right) /\left(\mathrm{x}_{\mathrm{fl}}-\mathrm{x}_{\mathrm{p}}\right)$ using a threshold of $4 \mathrm{~kW} / \mathrm{m}^{2}$ to define flame height: (a) experimental data, (b) numerical results for different pyrolysis lengths. Figure 7: Wall heat flux as function of $\left(\mathrm{x}-\mathrm{x}_{\mathrm{p}}\right) /\left(\mathrm{x}_{\mathrm{fl}}-\mathrm{X}_{\mathrm{p}}\right)$ using a threshold of $10 \mathrm{~kW} / \mathrm{m}^{2}$ to define flame height: (a) experimental data, (b) numerical results for different pyrolysis lengths.

Figure 8: Wall heat flux as function of $\left(\mathrm{x}-\mathrm{x}_{\mathrm{p}}\right) /\left(\mathrm{x}_{\mathrm{fl}}-\mathrm{X}_{\mathrm{p}}\right)$ using the correlations of: (a) Delichatsios [8], (b) Hasemi et al. [7], (c) Orloff et al. [4] and d) Tewarson and Ogden [6] to define flame height.

Figure 9: $\Delta \dot{Q}_{t}^{\prime} / \dot{Q}_{t}^{\prime}$ as function of $\mathrm{x}_{\mathrm{p}}$ 
Table1. Summary of the key equations expressed in generic form. In this table, $\Phi$ is the generic fluid property, $\Gamma_{\Phi}$ and $S_{\Phi}$ the exchange coefficient and source terms.

\begin{tabular}{cccc}
\hline Transport of & $\Phi$ & $\Gamma_{\Phi}$ & $\mathrm{S}_{\Phi}$ \\
\hline Mass & 1 & 0 & 0 \\
\hline Momentum & $u_{i}$ & $\frac{\partial p_{d}}{\partial x_{i}}+\left(\rho-\rho_{\infty}\right) g_{i}$ \\
\hline $\begin{array}{c}\text { Enthalpy } \\
\text { Turbulence }\end{array}$ & $h$ & $+\frac{\partial}{\partial x_{j}}\left[\mu_{\text {eff }}\left(\frac{\partial u_{i}}{\partial x_{j}}+\frac{\partial u_{j}}{\partial x_{i}}\right)\right]$ \\
\hline $\begin{array}{c}\text { Rate of Dissipation } \\
\text { of Turbulent Energy }\end{array}$ & $\varepsilon$ & $-\frac{\partial}{\partial x_{j}}\left[\frac{2}{3} \mu_{e f f} \frac{\partial u_{k}}{\partial x_{k}} \delta_{i j}\right]$ \\
\hline $\begin{array}{c}\text { Soot Volume } \\
\text { Fraction }\end{array}$ & $f_{\text {soot }}+\frac{\mu \sigma_{t}}{\sigma_{t}}$ & $-\frac{\partial q_{r j}}{\partial x_{j}}$ \\
\hline $\begin{array}{c}\text { Soot Number } \\
\text { Density }\end{array}$ & $n_{\text {soot }}$ & $\mu_{t}$ & $P_{k}+W_{k}-\rho \varepsilon$ \\
\hline $\begin{array}{c}\text { Species Mass } \\
\text { Fraction }\end{array}$ & $Y_{\alpha}$ & $\frac{\mu_{t}}{\sigma_{\varepsilon}}$ & $\left(C_{\varepsilon 1}-R\right) \frac{\varepsilon}{k} P_{k}-C_{\varepsilon 2} \rho \frac{\varepsilon^{2}}{k}$ \\
\hline
\end{tabular}

where

$$
\begin{gathered}
\mu_{t}=\rho C_{\mu} \frac{k^{2}}{\varepsilon} \quad \mu_{e f f}=\mu+\mu_{t} \quad P_{k}=-\left[\mu t\left(\frac{\partial u_{i}}{\partial x_{j}}+\frac{\partial u_{j}}{\partial x_{i}}\right)-\frac{2}{3}\left(\mu_{t} \frac{\partial u_{k}}{\partial x_{k}} \delta_{i j}+\rho k\right)\right] \frac{\partial u_{i}}{\partial x_{j}} \\
W_{k}=-\beta g \frac{\mu_{t}}{\sigma_{t}} \frac{\partial T}{\partial x_{j}} \quad R=\frac{\eta\left(1-\eta / \eta_{0}\right)}{1+\beta \eta^{3}} \quad \eta=\sqrt{\left|\frac{P_{k}}{\rho C_{\mu} \varepsilon}\right|} \quad \eta_{0}=4.38 \quad \beta=0.015 \\
C_{\mu}=0.0845
\end{gathered}
$$$$
\sigma_{k}=0.7179 \quad \sigma_{\varepsilon}=0.7179 \quad \sigma_{f}=\sigma_{t}=0.7 \quad S C=\operatorname{Pr}=0.71 \quad C_{\varepsilon 1}=1.42 \quad C_{\varepsilon 2}=1.68
$$

\section{$C_{\varepsilon 3}=1.5$}


Table2. Correlation of the form $\mathrm{x}_{\mathrm{fl}}=\mathrm{a}\left(\mathrm{x}_{\mathrm{p}}\right)^{\mathrm{n}}$ with both $\mathrm{x}_{\mathrm{fl}}$ and $\mathrm{x}_{\mathrm{p}}$ in centimetre units

\begin{tabular}{ccc}
\hline Correlations & $\mathrm{a}$ & $\mathrm{n}$ \\
\hline Delichatsios [8] & 4.42 & 0.802 \\
\hline Hasemi et al. [7] & 2 & 1 \\
\hline Orloff et al. [4] & 5.346 & 0.781 \\
\hline Tewarson and Ogden [6] & 4.22 & 0.7 \\
\hline
\end{tabular}




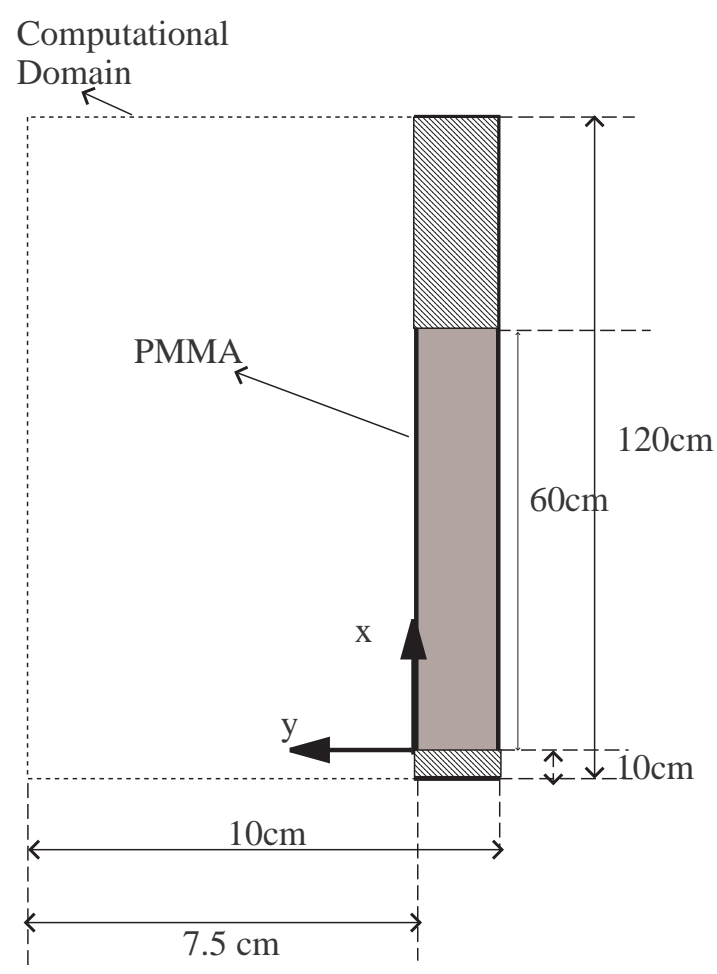

Figure 1: A schematic of the physical problem. 
(a)

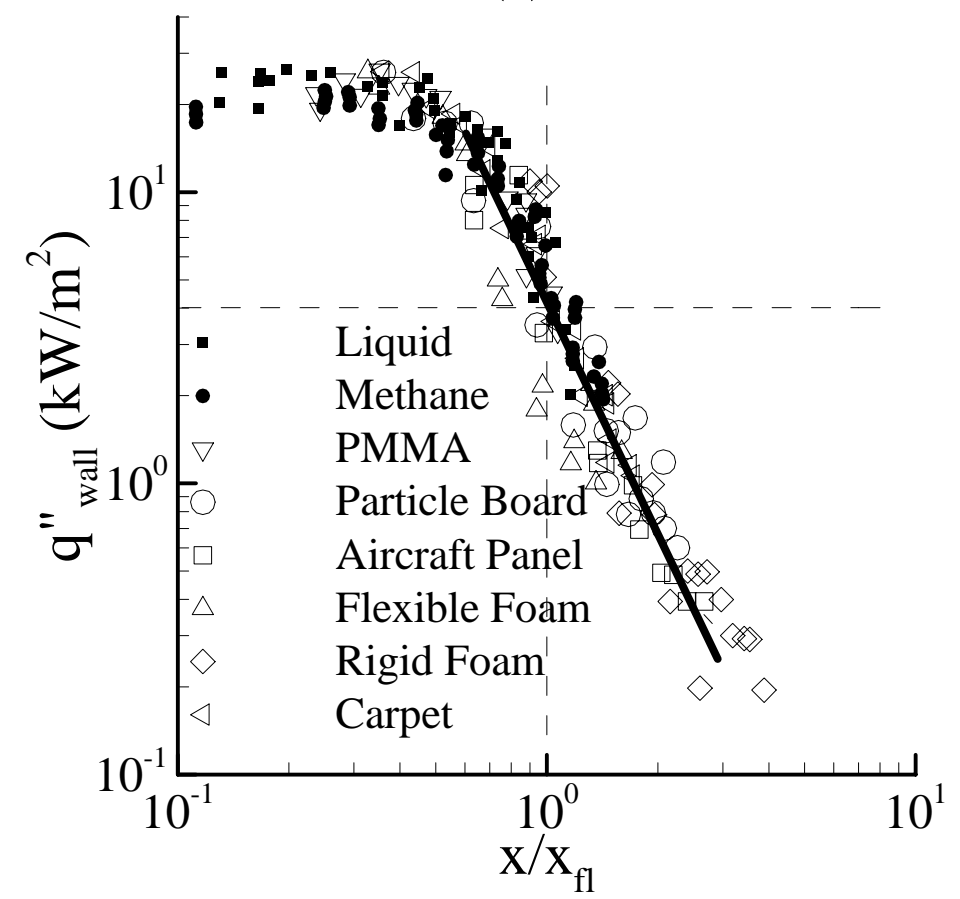

(b)

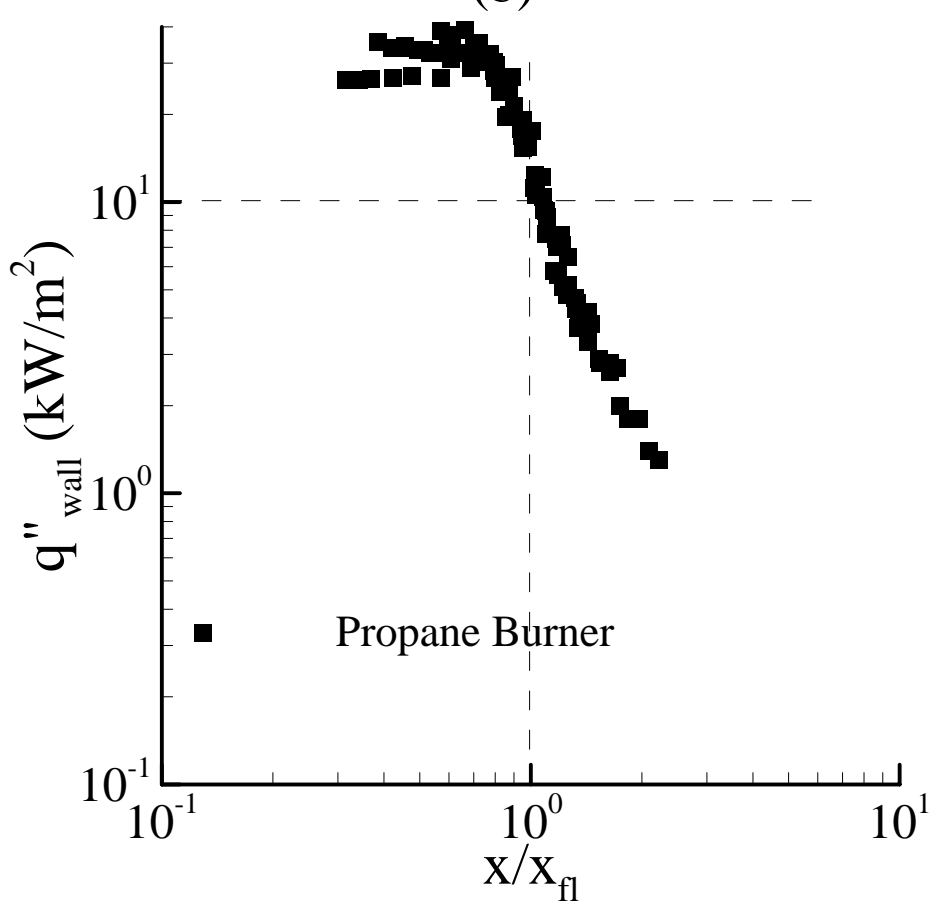

Figure2: Wall heat flux as function of $\mathrm{x} / \mathrm{x}_{\mathrm{fl}}$ : (a) Experimental data from Ref. [13]- [15], (b)

Experimental data from Ref. [10]. 


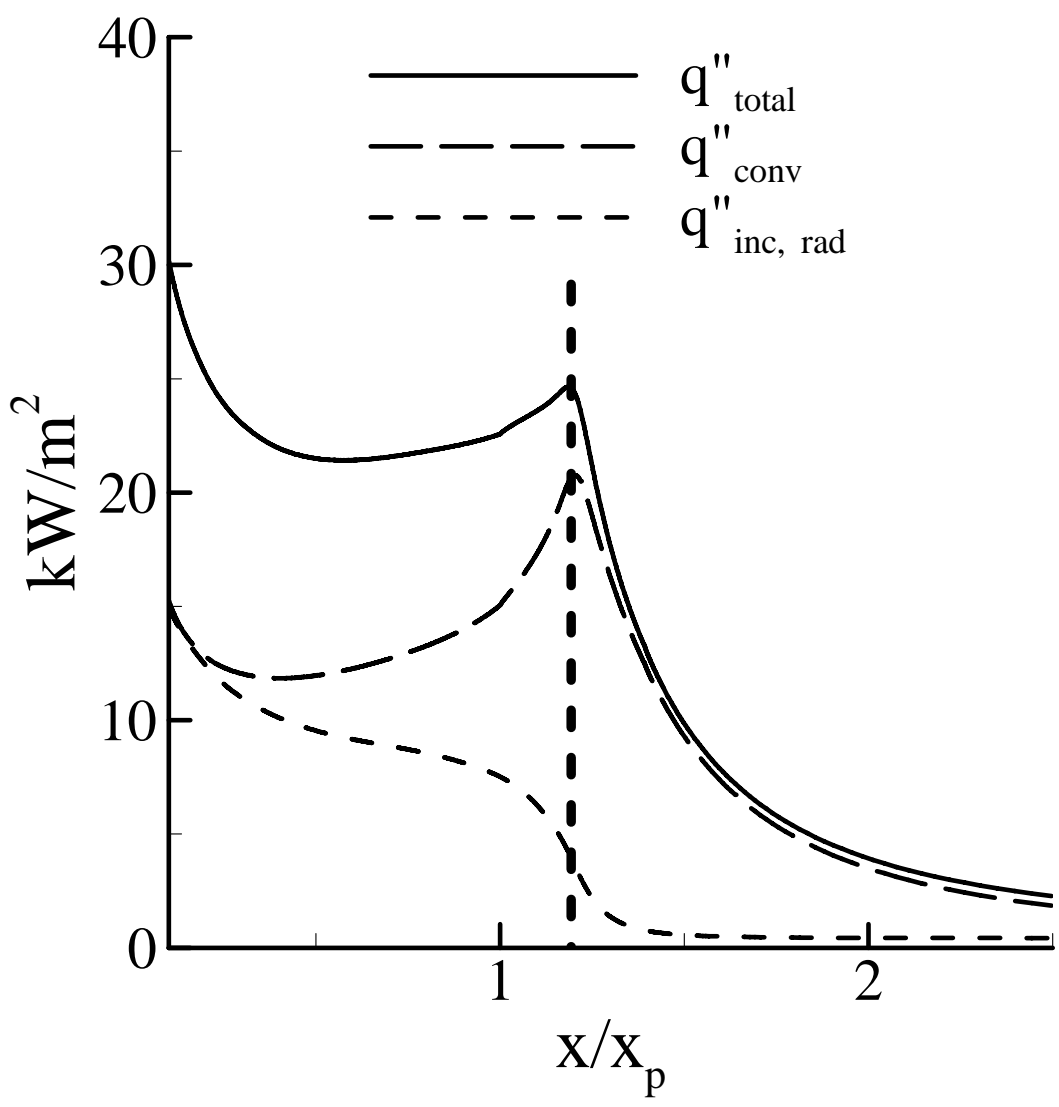

Figure 3: Total, incident radiative, and convective heat fluxes as function of $\mathrm{x} / \mathrm{x}_{\mathrm{p}}$. 


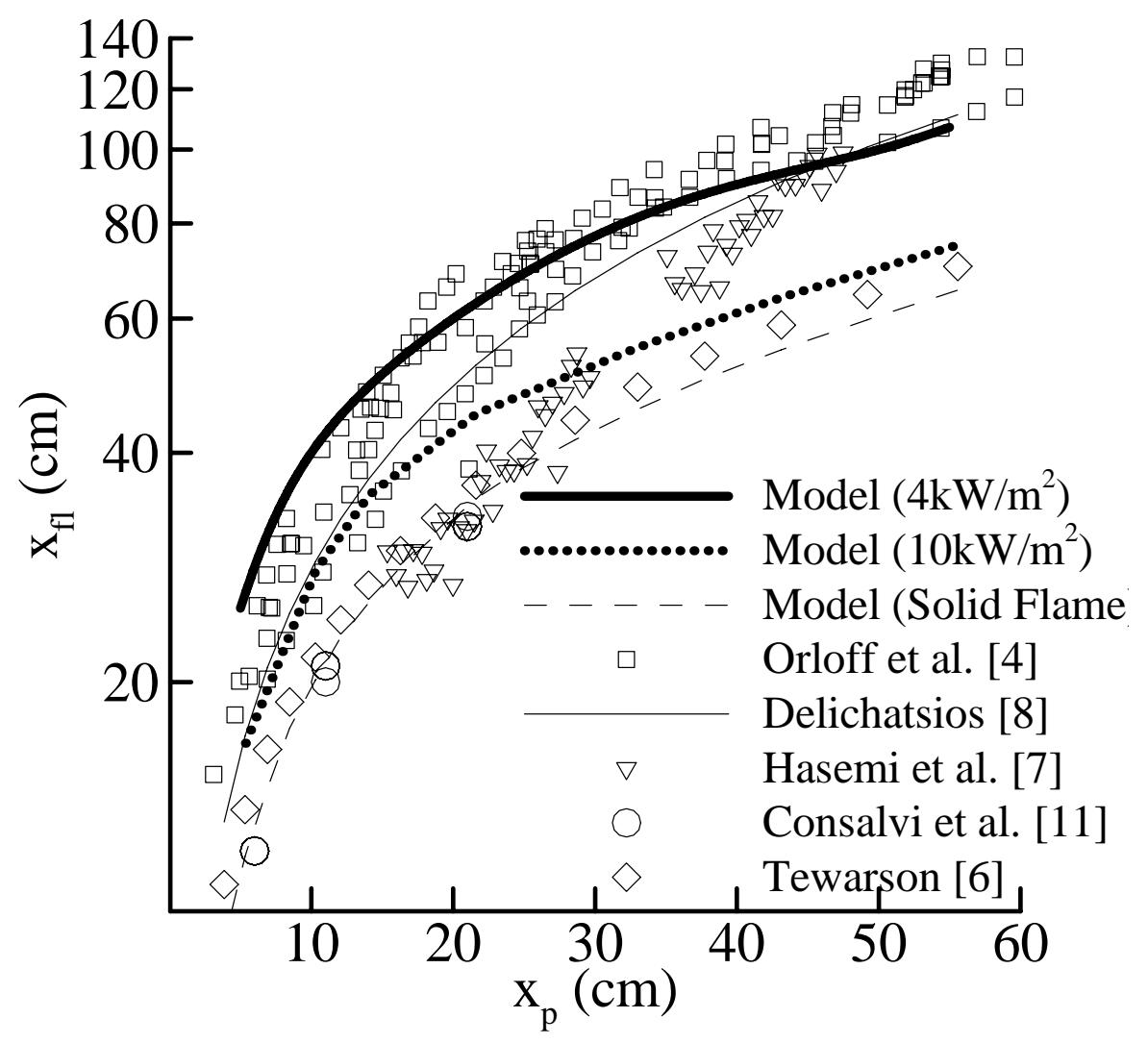

Figure 4: Flame height as function of the pyrolysis length. 

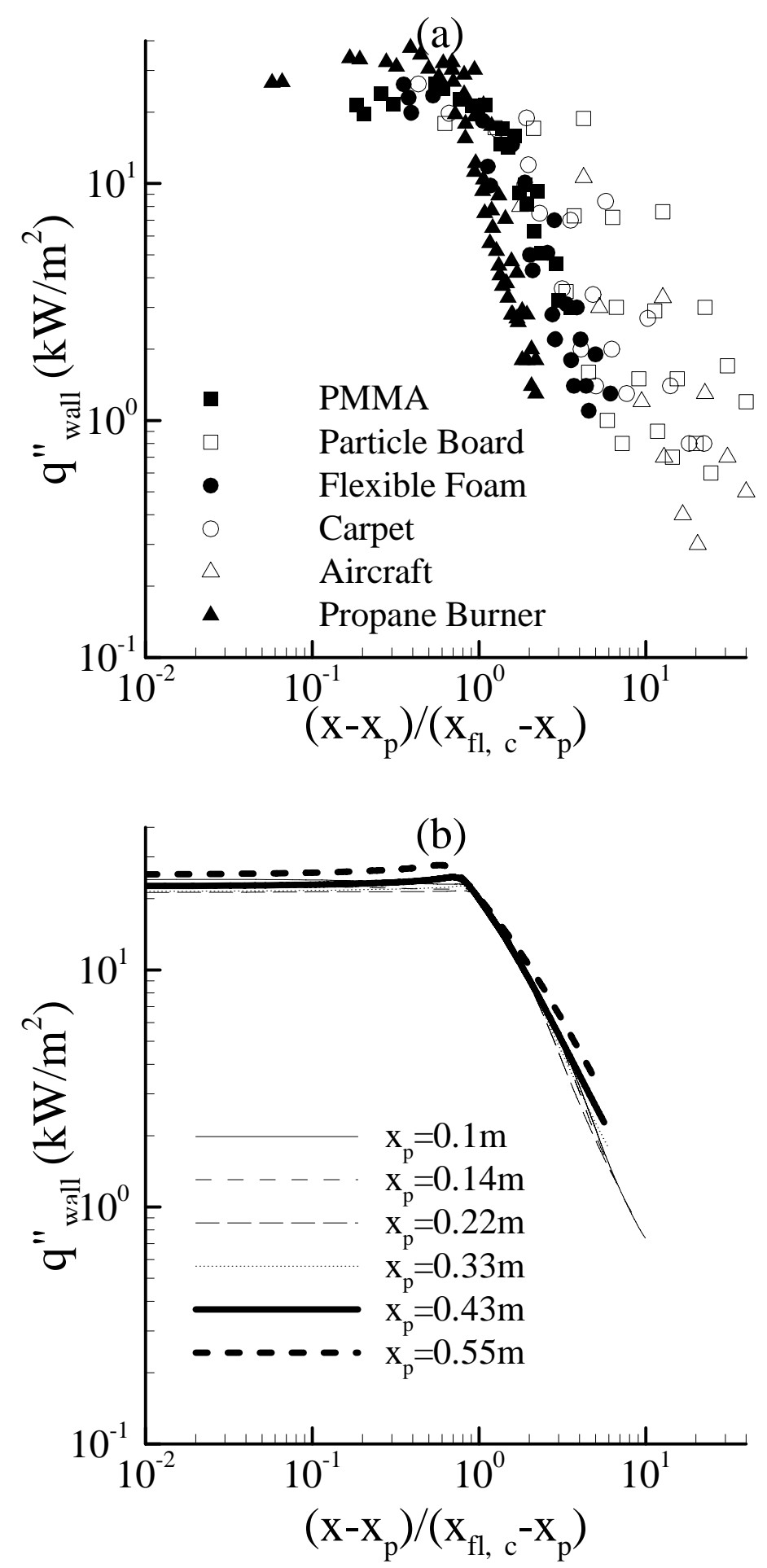

Figure 5: Wall heat flux as function of $\left(\mathrm{x}-\mathrm{x}_{\mathrm{p}}\right) /\left(\mathrm{x}_{\mathrm{fl}}-\mathrm{x}_{\mathrm{p}}\right)$ using the continuous flame to define flame height: (a) experimental data, (b) numerical results for different pyrolysis lengths. 


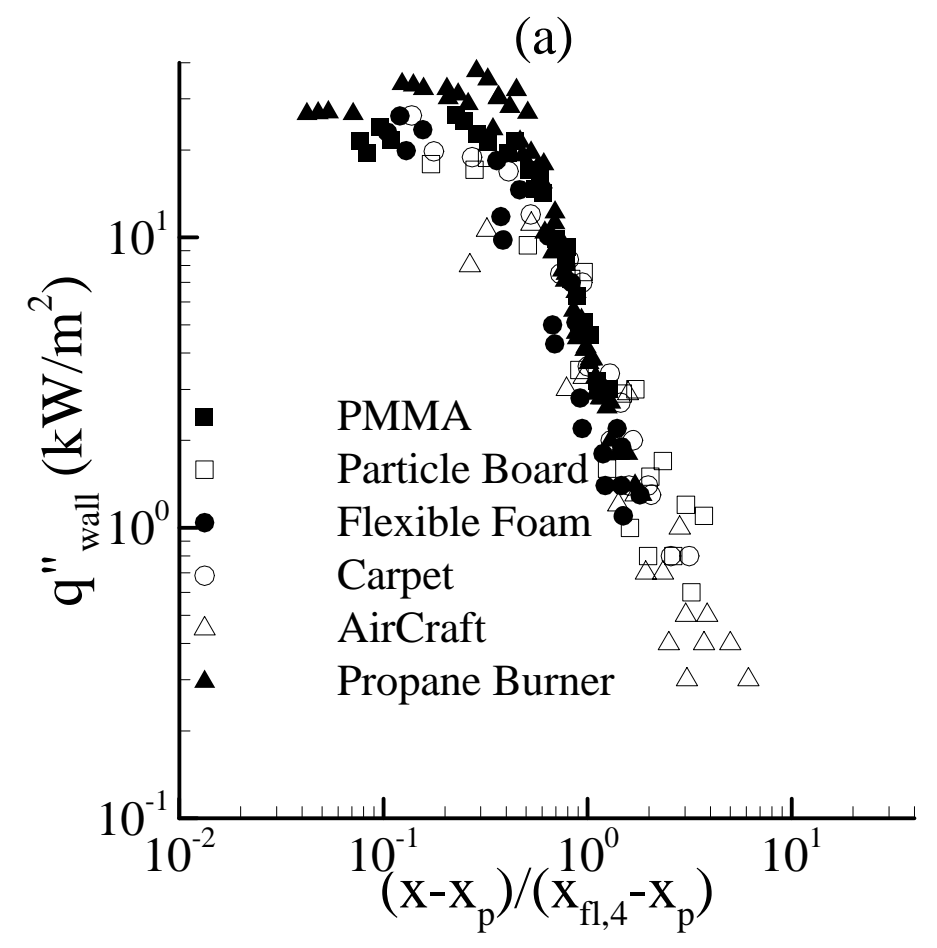

(b)

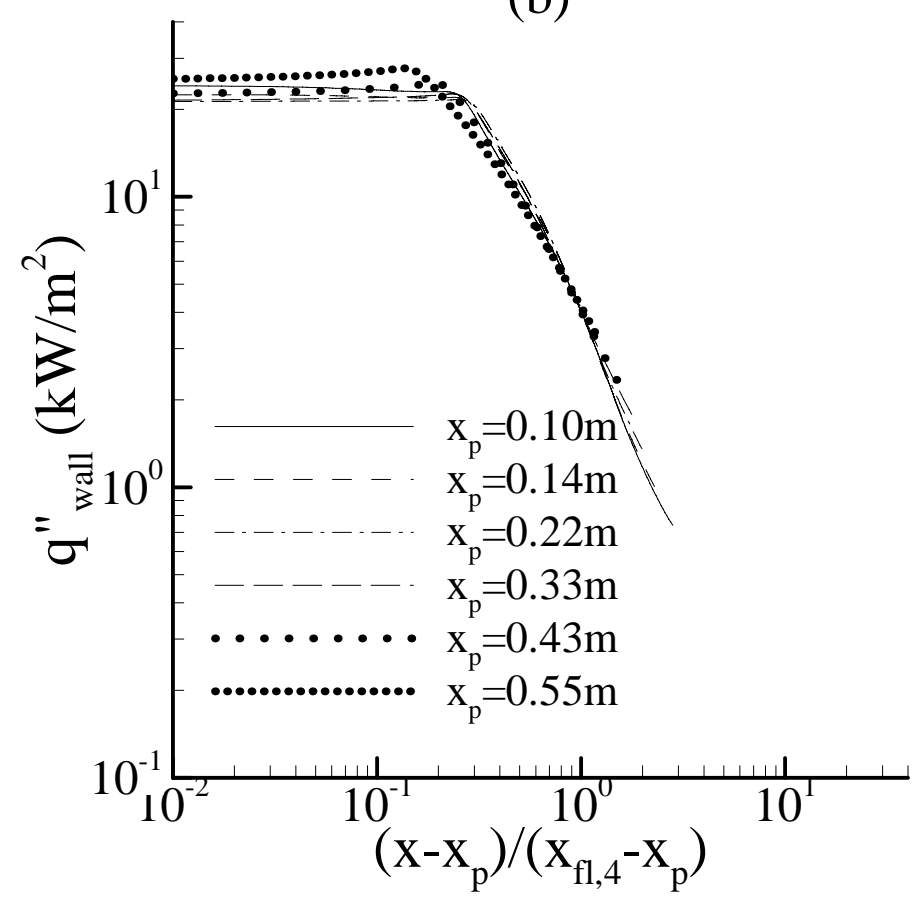

Figure 6: Wall heat flux as function of $\left(\mathrm{x}-\mathrm{x}_{\mathrm{p}}\right) /\left(\mathrm{x}_{\mathrm{fl}}-\mathrm{x}_{\mathrm{p}}\right)$ using a threshold of $4 \mathrm{~kW} / \mathrm{m}^{2}$ to define flame height: (a) experimental data, (b) numerical results for different pyrolysis lengths. 


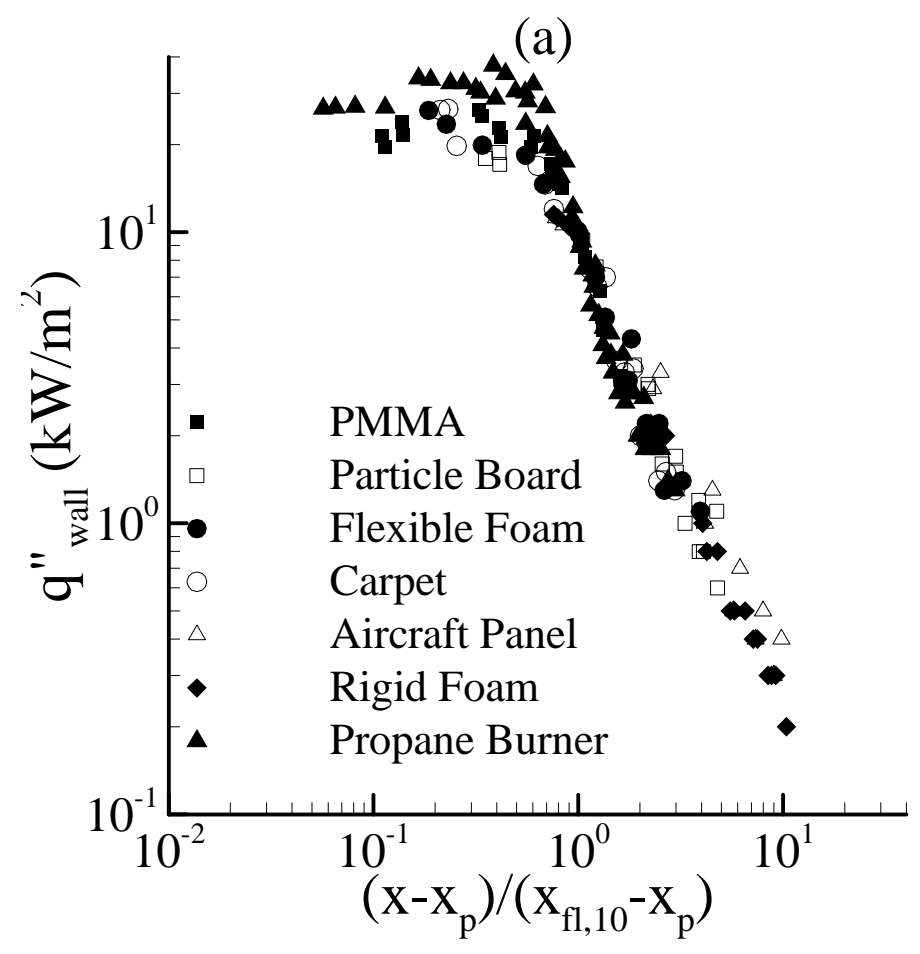

(b)

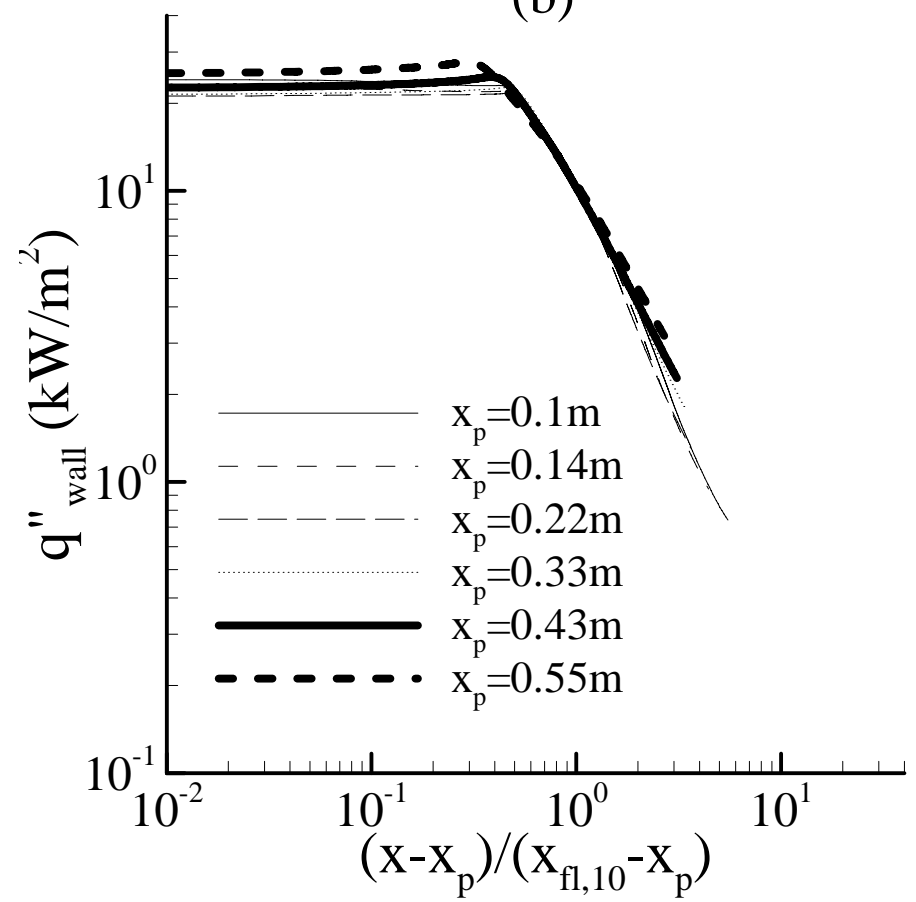

Figure 7: Wall heat flux as function of $\left(\mathrm{x}-\mathrm{x}_{\mathrm{p}}\right) /\left(\mathrm{x}_{\mathrm{fl}}-\mathrm{x}_{\mathrm{p}}\right)$ using a threshold of $10 \mathrm{~kW} / \mathrm{m}^{2}$ to define flame height: (a) experimental data, (b) numerical results for different pyrolysis lengths. 


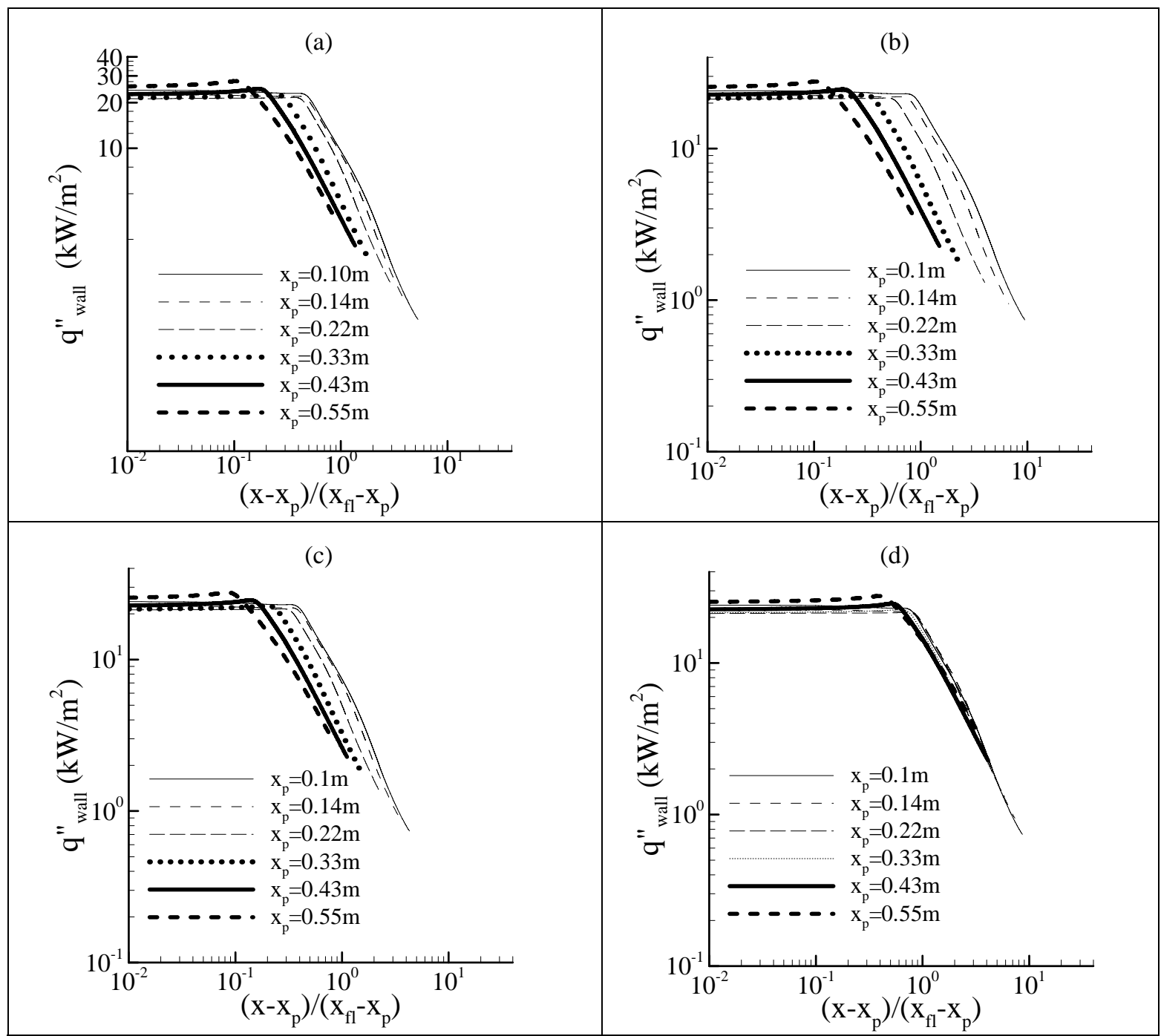

Figure 8: Wall heat flux as function of $\left(\mathrm{x}-\mathrm{x}_{\mathrm{p}}\right) /\left(\mathrm{x}_{\mathrm{fl}}-\mathrm{x}_{\mathrm{p}}\right)$ using the correlations of: (a)

Delichatsios [8], (b) Hasemi et al. [7], (c) Orloff et al. [4] and d) Tewarson and Ogden [6] to define flame height. 


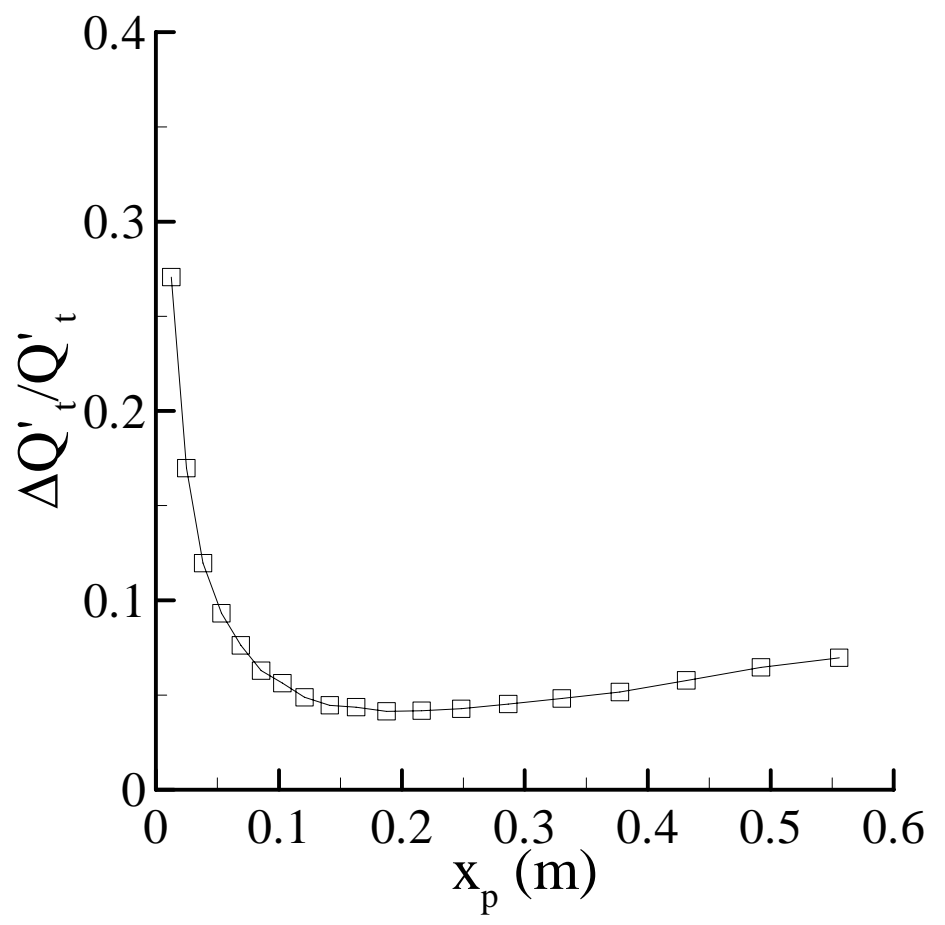

Figure 9: $\Delta \dot{Q}_{t}^{\prime} / \dot{Q}_{t}^{\prime}$ as function of $\mathrm{x}_{\mathrm{p}}$ 